\title{
Proposal to Prevent Alcohol Dependence Using Purpose in Life/Ikigai to Mimic the Chemical Effects of $\beta$-Endorphin
}

\author{
Riichiro Ishida \\ 321-8 Akasabi, Nishikan-ku, Niigata, Japan \\ Email: ishida-riichiro@hb.tp1.jp \\ Received April $7^{\text {th }}, 2012$; revised May $2^{\text {nd }}, 2012$; accepted May $30^{\text {th }}, 2012$
}

\begin{abstract}
Purpose in life (PIL)/ikigai is a social attitude based on the concept that, "every person has a need to establish meaning in life". Comfort and pleasure are related to the secretion of neurotransmitters such as serotonin, dopamine and $\beta$-endorphin. Drinking alcohol can also trigger emotions and cause the secretion of $\beta$-endorphin. Persons, who have an inner sense of satisfaction, do not need or want to induce comfort and pleasure by using alcohol or morphine. The primary chemical structures of $\beta$-endorphin and morphine are similar. Therefore, it is possible that helping people to achieve PIL/ikigai could strengthen psychological and/or physical defenses against alcohol dependence.
\end{abstract}

Keywords: Purpose in Life/Ikigai; Alcohol Dependence; Pleasure; Anxiety; $\beta$-Endorphin

\section{Introduction}

It is normal for a person to have ambition and to seek pleasure, comfort, and less anxiety (Diener, 1984; Kraut, 1979; Lu, Gilmour, Kao, Weng, Hu, Chem, Huang, \& Shin, 2001). These behaviors indicate an active healthy brain and secretion of neurotransmitters which control the mind (Chaouloff, 1989; Comings \& Blum, 2000; Esch \& Stefano, 2010; Dalayeun, Norès, \& Bergal, 1993). Successful adaptation to the environment causes pleasure and comfort which relate to a well balanced secretion of neurotransmitters such as serotonin, dopamine, noradrenaline, and $\beta$-endorphin (Chaouloff, 1989; Esch \& Stefano, 2010). Anxiety is a signal that tells the individual to make adjustments to changes in the environment and situation (Selye, 1936, 1973) and causes an imbalance of neurotransmitters (Costa-Pinto \& Palemo-Neto, 2010; Chaouloff, 1989).

Recently, two social attitudes, purpose in life (PIL) and ikigai, have been found to be related to ambition, comfort, pleasure and decreased anxiety even during various kinds of stressful situations (e.g., Ishida, 2008; Ishida, 2011, 2012; Ishida, Okada, \& Bando, 2004). Drinking alcohol also causes comfort and pleasure and decreased anxiety (Dalayeun, Norès, \& Bergal, 1993). PIL/ikigai (Ishida, 2012) and drinking alcohol (Dalayeun, Norès, \& Bergal, 1993) are both accompanied by the secretion of $\beta$-endorphin.

Alcohol dependence is an important and serious issue in most countries. Therefore we propose that psychologically and physiologically methods can be used to prevent alcohol dependence.

\section{Frontal Lobe and Neurotransmitters}

The frontal lobe, especially the prefrontal lobe, is more evolved in humans than in other mammals (Brodal, 1998; Brown, Keynes, \& Lumsden, 2001). The prefrontal lobe connects with other areas of the brain via neuronal networks (Bro- dal, 1998; Brown, Keynes, \& Lumsden, 2001) and plays a role in ambition and mental integration functions (Brodal, 1998; Brown, Keynes, \& Lumsden, 2001). Therefore, PIL/ikigai is thought to be a frontal lobe function (Ishida, 2012). In addition to internal need, repeated environmental stimulation strengthens the neuronal network (Mathon, Kamal, Smidt, \& Ramakers, 2003). This process is related to repeated secretion of neurotransmitters (Mathon, Kamal, Smidt, \& Ramakers, 2003). Serotonin as a neurotransmitter relates to the control of well balanced emotion, dopamine relates to motivation and pleasure, noradrenaline relates to anxiety and $\beta$-endorphin relates to decreasing pain and increasing comfort (Chaouloff, 1989; Comings \& Blum, 2000; Costa-Pinto \& Palemo-Neto, 2010; Dalayeun, Norès, \& Bergal, 1993; Esch \& Stefano, 2010; Mathon, Kamal, Smidt, \& Ramakers, 2003). Therefore, personality manifestations based on social attitudes, i.e., PIL/ikigai, could depend on the neuronal network activity caused by the secretion of neurotransmitters (Böning, 2009).

\section{Stress}

Selye proposed that stress included psychological, physical, and chemical factors (Selye, 1936, 1973). The autonomic nervous system helps the body adjust to changes in the environment and the person's situation, a defense mechanism referred to as homeostasis (Cannon, 1939). Stress can cause a non-specific response in the internal organs, such as adrenal cortex hypertrophy (Selye, 1936, 1973). Stress can also cause anxiety and an imbalance in the autonomic nervous system (Masaoka, Onaka, Shimizu, Sakurai, \& Homma, 2007; Nagai, Wada, \& Sunaga, 2002; Pollatos, Werner, Duscheck, Schandry, Matthias, Traut-Mattausch, \& Herbert, 2011). Anxiety accompanied by internal responses is a signal for the person to adjust to these changes, i.e., stress (Selye, 1936, 1973). Ignoring the signals and excessive continuous stress can cause disruption of the homeostasis function leading to psychiatric and somatic 
disease and sometimes death (Selye, 1936, 1973).

\section{Mechanism of Purpose in Life (PIL) and Ikigai}

PIL is drawn from existentialism that was developed in Europe (Ishida, 2011). Ikigai is a Japanese concept that dates back to the 14th century (Ishida, 2011). Both terms commonly propose the following: "Everything changes. Life is a onetime only event. Thus, every person has a natural and intrinsic need to achieve a meaningful life" (Ishida, 2011). Some psychological instruments for the measurement of PIL and ikigai have been developed (e.g., Crumbaugh \& Maholick, 1964; Sato \& Tanaka, 1974). Our studies show that PIL/ikigai negatively correlates with anxiety, psychiatric and somatic symptoms, and the need for approval from others (Ishida, 2011; Ishida, 2012). $\mathrm{PIL} /$ ikigai form a mechanism for the integration of psychologically stressful events in the past, present and future with less anxiety and less conflicts even during stressful situations (Ishida, 2011; Ishida, 2012). Additionally, PIL/ikigai provides a person with the ability to delay gratification, appreciate another's point of view, trust in a higher power, accept personal limitations, or count personal blessings (Ishida, 2011; Ishida, 2012). PIL/ikigai develops through positive experiences that occur from infancy to adolescence, such as spending time in beautiful natural surroundings, empathetic acceptance from others, and affection from others (Ishida, 2011; Ishida, 2012). On the other hand, excessive need for approval from others causes anxiety and conflict during stressful situations (Ishida, 2011; Ishida, 2012). Excessive need for approval from others develops when children are subject to excessive expectations from parents and teachers (Ishida, 2011; Ishida, 2012). There is strong evidence that PIL/ikigai can induce a physiological secretion of serotonin, dopamine, noradrenaline, and $\beta$-endorphin. Persons with PIL/ikigai are likely to demonstrate more independent spirit compared to those with excessive need for approval from others.

\section{Mechanism of Alcohol Dependence}

Recent studies show that the $\beta$-endorphin system controls alcohol consumption (Dalayeun, Norès, \& Bergal, 1993; Gianoulakis, Krishnan, \& Thavundayil, 1996; Morales-Mulia, de Cortari, Amaya, \& Méndez, 2012). Additionally, variation of $\beta$-endorphin secretion depends on drinking habits (Gianoulakis, Krishnan, \& Thavundayil, 1996; Morales-Mulia, de Cortari, Amaya, \& Méndez, 2012). Persons with PIL/ikigai show less anxiety, while those without PIL/ikigai demonstrate more anxiety (Ishida, 2011; Ishida, 2012). PIL/ikigai causes secretion of serotonin, dopamine, and $\beta$-endorphin (Ishida, 2012). Persons who have an internal sense of satisfaction are more likely to experience spontaneous feelings of pleasure and therefore they do not wish to drink alcohol or take morphine to alleviate pain (Nakata, 2006). Persons with anxiety attempt to induce pleasure by drinking alcohol (Dalayeun, Norès, \& Bergal, 1993). PIL/ ikigai triggers secretion of neurotransmitters such serotonin, dopamine, and $\beta$-endorphin. Likewise, the brain reacts to alcohol with a similar neurotransmitter response. The primary structure of morphine and $\beta$-endorphin are comparable (Dragon, Seidah, Lis, Routhier, \& Chrétien, 1977). By natural or chemically induced means, there is evidence that indicates that every person naturally seeks comfort, pleasure, and decreased anxiety. Successful treatment for addiction of drugs or alcohol (or other types of addiction) results in the addicted individual's ability to experience an internal sense of pleasure, self-belief and selfefficacy (Levinthal, 1988; Peele, 1990-1991). This evidence suggests that establishing PIL/ikigai by positive experiences could prevent alcohol dependence. Additionally positive experiences, such as spending time in beautiful natural surroundings and acceptance of warm empathetic attitudes from others helps persons to establish PIL/ikigai.

\section{Future Study}

Regardless of the importance of the alcohol dependence issue, the previous studies described above were studies about individuals. Other possible factors that influence alcohol dependence must also be considered. Therefore, totally integrated studies using experimental and epidemiological methods should be performed in the future; these studies include the chemical traits of neurotransmitters, development of PIL/ikigai and anxiety, alcohol dependence, effects of counseling for persons with alcohol dependence, and other possible factors influencing alcohol dependence. Additionally, other issues such as drug dependence, gambling problems, and the excessive need for approval from others which causes greater anxiety should be clarified.

\section{Conclusion}

Every person has a natural need to have pleasure and comfort and to avoid anxiety. PIL/ikigai relates to the inner aspects of the brain, while drinking alcohol is an external and artificial mechanism. Both PIL/ikigai and drinking alcohol result in pleasure and comfort and secretion of $\beta$-endorphin. Therefore, we suggest that helping individuals to achieve PIL/ikigai may be one method of deterring alcohol dependence.

\section{REFERENCES}

Böning, J. (2009). Addiction memory as a specific, individually learned memory imprint. Pharmacopsychiatry, 42, 66-68. doi:10.1055/s-0029-1216357

Brodal, P. (1998). The central nervous system (2nd ed.). New York: Oxford University Press.

Brown, M., Keynes, R., \& Lumsden, A. (2001). The developing brain. New York: Oxford University Press.

Cannon, W. B. (1939). The wisdom of the body. New York: WW Norton and Company.

Chaouloff, F. (1989). Physical exercise and brain monoamines: A review. Acta Physiologica Scandinavica, 137, 1-13. doi:10.1111/i.1748-1716.1989.tb08715.x

Comings, D. E., \& Blum, K. (2000). Reward deficiency syndrome: Genetic aspects of behavioral disorders. Progress in Brain Research, 126, 325-341. doi:10.1016/S0079-6123(00)26022-6

Costa-Pinto, F. A., \& Palemo-Neto, J. (2010). Neuroimmune interactions in stress. Neuroimmunomodulation, 17, 196-199. doi:10.1159/000258722

Crumbaugh, J. C., \& Maholick, L. T. (1964). An experimental study in existentialism: The psychometric approach to Frankl's concept of noogenic neurosis. Journal of Clinical Psychology, 20, 200-207. doi:10.1002/1097-4679(196404)20:2<200::AID-JCLP2270200203> 3.0.CO;2-U

Dalayeun, J. F., Norès, J. M., \& Bergal, S. (1993). Physiology of betaendorphins: A close-up view and a review of the literature. Biomedicine \& Pharmacotherapy, 47, 311-320. doi:10.1016/0753-3322(93)90080-5

Diener, E. (1984). Subjective well-being. Psychological Bulletin, 95, 
542-575. doi:10.1037/0033-2909.95.3.542

Dragon, N., Seidah, N. G., Lis, M., Routhier, R., \& Chrétien, M. (1977). Primary structure and morphine-like activity of human beta-endorphin. Canadian Journal of Biochemistry, 55, 666-670. doi:10.1139/077-096

Esch, T., \& Stefano, G. B. (2010). The neurobiology of stress management. Neuro Endocrinology Letters, 31, 19-39.

Gianoulakis, C., Krishnan, B., \& Thavundayil, J. (1996). Enhanced sensitivity of pituitary beta-endorphin to ethanol in subjects at high risk of alcoholism. Archives of General Psychiatry, 53, 250-257. doi:10.1001/archpsyc.1996.01830030072011

Ishida, R. (2008). Correlation between social desirability and autonomic nervous function under goal-oriented stress (mental arithmetic) with consideration of parental attitudes. The Autonomic Nervous System (Tokyo), 45, 242-249 (in Japanese).

Ishida, R. (2011). Enormous earthquake in Japan: Coping with stress using purpose in life/ikigai. Psychology, 2, 773-776. doi:10.4236/psych.2011.28118

Ishida, R. (2012). Purpose in life (ikigai), a frontal lobe function, is a natural and mentally healthy way to cope with stress. Psychology, 3, 272-276. doi:10.4236/psych.2012.33038

Ishida, R., Okada, M., \& Bando, T. (2004). Relation between level of purpose-in-life and the autonomic nervous function under a mental stress. Niigata Igakkai Zasshi, 118, 333-339 (in Japanese).

Kraut, R. (1979). Two conception of happiness. The Philosophical Review, 88, 167-107. doi:10.2307/2184505

Levinthal, C. F. (1988). Messengers of paradise: Opiates and the brain. New York: Doubleday.

Lu, L., Gilmour, R., Kao, S. F., Weng, T. H., Hu, C. H., Chem, J. G., Huang, S. E., \& Shin, J. B. (2001). Two ways to achieve happiness: When the East meets the West. Personality and Individual Differences, 30, 1161-1174. doi:10.1016/S0191-8869(00)00100-8

Mathon, D. S., Kamal, A., Smidt, M. P., \& Ramakers, G. M. (2003).
Modulation of cellular activity and synaptic transmission in the ventral tegmental area. European Journal of Pharmacology, 480, 97-115. doi:10.1016/j.ejphar.2003.08.097

Masaoka, Y., Onaka, Y., Shimizu, Y., Sakurai, S., \& Homma, I. (2007). State anxiety dependent on perspiration during mental stress and deep inspiration. The Journal of Physiological Sciences, 57, 121-126. doi:10.2170/physiolsci.RP000607

Morales-Mulia, M., De Gortari, P., Amaya, M. I., \& Méndez, M. (2012). Activity and expression of enkephalinase and aminopeptidase $\mathrm{N}$ in regions of the mesocorticolimbic system are selectively modified by acute ethanol administration. Journal of Molecular Neuroscience: MN, 46, 58-67. doi:10.1007/s12031-011-9623-2

Nagai, M., Wada, M., \& Sunaga, N. (2002). Trait anxiety affects the papillary light reflex in college students. Neuroscience Letters, 328, 68-70. doi:10.1016/S0304-3940(02)00373-7

Nakata, Y. (2006). Nounai-bussitsu kara nani wo manabuka? In: NPO Hojin Nou no seiki suisin kaigi (Eds.), Kokoro no yamai/Nou no yamai (pp. 29-46). Tokyo: Kubapuro (in Japanese).

Peele, S. (1990-1991). What works in addiction treatment and what doesn't: Is the best therapy no therapy? The International Journal of the Addictions, 25, 1409-1419.

Pollatos, O., Werner, N. S., Duscheck, S., Schandry, R., Matthias, E., Traut-Mattausch, E., \& Herbert, B. M. (2011). Differential effects of alexithymia subscales on autonomic reactivity and anxiety social stress. Journal of Psychosomatic Research, 70, 525-533. doi:10.1016/j.jpsychores.2010.12.003

Sato, F., \& Tanaka, H. (1974). An experimental study on the existential aspect of life (Part I): The cross-cultural approach to purpose in life. Tohoku Psychologica Folia, 33, 20-46.

Selye, H. (1936). A syndrome produced by diverse nocuous agents. Nature, 138, 32. doi:10.1038/138032a 0

Selye, H. (1973). The evolution of the stress concept. American Psychologist, 61, 692-699. 